\section{UM OLHAR SOBRE A PATOLOGIZAÇÃO DA INFÂNCIA A PARTIR DO CAPSI}

\author{
A Look at Children Pathologization through the CAPSi \\ Una Mirada Sobre la Patologización de la Infancia a partir \\ del CAPSi
}

\author{
Un Regard Vers la Pathologisation de L'enfance à partir du \\ CAPSi
}

Resumo

A infância, no decorrer da história, foi ocupando lugar na produção do saber e do poder psiquiátrico, tornando-se alvo de investimentos das políticas públicas. No Brasil, a institucionalização do Sistema Único de Saúde (SUS), do Estatuto da Criança e do Adolescente (ECA) e da Reforma Psiquiátrica constitui-se um marco para a reorganização do cuidado em saúde mental para crianças e adolescentes. A compreensão da produção da infância passa pelos processos de desinstitucionalização das práticas de cuidado, do reconhecimento da criança como sujeito e a potência de criação de cada encontro. Este artigo problematiza a produção da infância a partir das práticas de cuidado no Centro de Atenção Psicossocial para infância e adolescência (CAPSi). Utilizamos a cartografia como estratégia metodológica, enfatizando o estudo da dimensão processual da subjetividade e de seu processo de produção. Acompanhamos as atividades em um CAPSi por quatro meses, realizando observações das ações desenvolvidas nesse serviço e grupos focais com os integrantes da equipe. Observamos que a patologização é um dos modos pelos quais a infância é produzida no CAPSi. Os processos de psiquiatrização e patologização da infância no percurso das crianças pelo CAPSi são percebidos nas diversas marcas impressas em seus processos de subjetivação. Uma dessas marcas ocorre pelo processo de atribuição de um diagnóstico às crianças. Afirmar o lugar do CAPSi como agenciador de novos encontros configura-se uma estratégia para que outras experiências sejam possíveis. O CAPSi é um lugar de encontro onde diversas instituições se cruzam, permitindo que o encontro das crianças se dê com cada uma dessas instituições que atravessam as práticas, tensionando a noção de identidade infantil como uma entidade criança, imóvel e universal. Isso permite que a criança seja um campo de forças e intensidades, inventando a sua experiência com o sofrimento e as práticas de cuidado.

Palavras-chave: infância; saúde mental; CAPSi; patologização; reforma psiquiátrica.

\begin{abstract}
Childhood, throughout history, has been taking place in the production of knowledge and psychiatric power, becoming a target for public policies investments. The institutionalization of the Unified Health System (SUS), the Statute of Child and Adolescent (ECA) and the Psychiatric Reform are, in Brazil, landmarks for the reorganization of mental health care for children and adolescents. The understanding of the production of childhood undergoes processes of deinstitutionalization of care practices, the recognition of children as individuals and the power of creating each meeting. This article problematizes the childhood production from care practices in a Psychosocial Care Center for children and adolescents (CAPSi). The research instrument used was the cartography, emphasizing the study of the procedural dimension of subjectivity and its production process. The activities in a CAPSi were followed for four months, conducting observations of the actions developed in this service and focus groups with team members. The pathologization is one of the ways in which childhood is produced in the CAPSi as it was observed in the study. The processes of childhood psychopathologization and pathologization are perceived in different marks printed in the
\end{abstract}

Artigo Original



1) Psicóloga. Professora do Departamento de Psicologia da Universidade Estadual do Centro Oeste (Unicentro), Campus Irati/PR. Mestre e Doutoranda em Psicologia Social e Institucional/ Universidade Federal do Rio Grande do Sul (UFRGS)

2) Professora do Instituto de Psicologia e do Programa de Pós-Graduação em Psicologia Social e Institucional da Universidade Federal do Rio Grande do Sul.

Recebido em: 16/11/2011 Revisado em: 02/10/2014 Aceito em: 02/10/2014 
processes of the children's subjectification. One of these marks occurs in the process of assigning a diagnosis to the children. Affirming that CAPSi is an agent for new meetings may be seen as a strategy, so that other experiences may become possible. CAPSi as the meeting place and a place where several institutions intersect allows the children's meeting to deal with each of these institutions that cross the practices, stressing the notion of child identity as an infant, static, and universal entity. This allows children to be a field of forces and intensities, inventing their experience through suffering and care practices.

Keywords: childhood; mental health; CAPSi; pathologization; psychiatric reform.

\section{Resumen}

En el transcurrir de la historia la infancia estuvo ocupando sitio en la producción del saber y del poder psiquiátrico, tornándose objetivo de investimentos de las políticas públicas. En Brasil, la institucionalización del Sistema Único de Salud (SUS), del Estatuto del Niño y del Adolescente (ECA) y de la Reforma Psiquiátrica, se constituye en punto de referencia para la reorganización del cuidado en salud mental de niños y adolescentes. La comprensión de la producción de la infancia pasa por los procesos de desinstitucionalización de las prácticas de cuidado, el reconocimiento del niño como sujeto, y la potencia de la creación de cada encuentro. Este artículo problematiza la producción de la infancia a partir de las prácticas de cuidado en el Centro de Atención Psicosocial para la infancia y adolescencia (CAPSi). Utilizamos la cartografía como estrategia metodológica, enfatizando el estudio de la dimensión procesual de la subjetividad y su proceso de producción. Seguimos las actividades en un CAPSi a lo largo de cuatro meses realizando observaciones de las acciones desarrolladas en ese servicio y grupos focales con los integrantes del equipo. Observamos que la patologización es uno de los modos por los cuales la infancia está producida en el CAPSi. Los procesos de psiquiatrización y patologización de la infancia en el recurrido de los niños por el CAPSi son percibidos en las diversas marcas que impresas en sus procesos de subjetivación. Una de esas marcas se da por el proceso de asignación de un diagnóstico a los niños. Afirmar la posición del CAPSi como administrador de nuevos encuentros se configura una estrategia para que otras experiencias sean posibles. El CAPSi es un sitio de encuentro donde diversas instituciones se cruzan permitiendo que el encuentro de los niños se dé con cada una de esas instituciones que cruzan las prácticas tensionando la noción de identidad infantil como una entidad niña, inmóvil y universal. Eso permite que el niño sea un campo de fuerzas e intensidades y que invente su experiencia con el sufrimiento y las prácticas del cuidado.

Palabras clave: infancia; salud mental; CAPSi ; patologización; reforma psiquiátrica.

\section{Résumé}

L'enfance, au cours de l'histoire, a eu de la place dans la production du savoir et du pouvoir psychiatrique en devenant la cible d'investissements des politiques publiques. Au Brésil, l'institutionalisation du Systhème Unique de Santé (SUS), du Statut de l'Enfant et de l'Adolescent (ECA) et de la réforme psychiatrique constitue un point fort de la réorganisation du soin de la santé mentale pour les enfants et les adolescents. La compréhension de la production de l'enfance passe par des processus de désinstitutionalisation des pratiques de soin, de la reconnaissance de l'enfant comme sujet, et la puissance de création de chaque rencontre. Cet article met em question la production de l'enfance à partir des pratiques de soin dans le Centre d'Attention Psychosocial pour l'enfance et l'adolescence (CAPSi). Nous avons utilisé la cartographie comme stratégie méthodologique en signalant l'étude de la dimension procédural de la subjectivité et de son processus de production. Nous avons accompagné les activités dans un CAPSi pendant quatre mois en y remarquant les actions développées et des groupes avec l'équipe. Nous avons remarqué que la pathologisation est l'un des modes par lequels l'enfance est produite dans le CAPSi. Les processus de psychiatrisation et celui de la pathologisation de l'enfance dans le parcours des enfants par le CAPSi sont aperçus dans des diverses marques imprimées dans leurs processus de subjectivation. L'une de ces marques se produit par le processus d'attribution d'un diagnostic aux enfants. Affirmer la place du CAPSi en tant qu'organisateur de nouvelles rencontres représente une stratégie pour que de nouvelles expériences soient possibles. Le CAPSi est un lieu de reencontre et où des plusieures institutions se croisent en permettant la reencontre des enfants avec chacune de ces institutions qui traversent les pratiques en tension avec la notion d'identité infantile comme une entité enfant, immobile et universel. Cela permet ainsi que l'enfant soit um champ de forces et d'intensités, en inventant son expérience avec la souffrance et les pratiques de soin.

Mots-clés: enfance; santé mentale; CAPSi; pathologisation; réforme psychiatrique.

No Brasil, observamos os avanços que o paradigma psicossocial imprimiu nas práticas de cuidado, principalmente de adultos, redesenhando a história da saúde mental para fora dos manicômios, em consonância com a construção de autonomia, do cuidado sem exclusão e de uma escuta centrada no sujeito e não no sintoma. Estudos abordam a influência dos Centros de Atenção Psicossocial (CAPS) na constituição e efetivação da Reforma Psiquiátrica (Kantorski et al, 2009; Onocko-Campos \& Furtado, 2006), mas poucos estudos trazem a questão da infância dentro desses equipamentos e o que vem sendo produzido ao longo de sua existência.

Este artigo apresenta os resultados de uma pesquisa cujo objetivo foi investigar a infância e sua produção a partir da problematização das práticas de cuidado em um Centro de Atenção Psicossocial para infância e adolescência (CAPSi) no estado do Rio Grande do Sul (RS). Buscaremos discutir como os CAPSi têm participado da produção da infância, ou da produção de certo "tipo" de infância, entendendo 
como os discursos e as práticas ali produzidos se conectam aos discursos da patologização infantil. Nosso interesse é trazer para o campo da problematização as práticas que constituem determinadas formas de cuidar e o que elas produzem.

A problematização proposta pela pesquisa ancora-se em alguns marcadores: a infância como produção social; os processos de patologização e institucionalização da infância; as práticas de cuidado no contexto do Sistema Único de Saúde - SUS, da Reforma Psiquiátrica e da vigência; e implementação do Estatuto da Criança e do Adolescente. Nesse cenário, insere-se a elaboração e execução de políticas públicas de saúde mental infantojuvenil. A política de atenção à saúde mental da criança e do adolescente prevê a implementação de CAPSi em municípios de médio e grande porte (Ministério da Saúde [MS], 2005). Sugere, ainda, que a rede substitutiva de serviços inclua o cuidado a esses sujeitos nos diferentes equipamentos de saúde. Os CAPS são serviços de saúde do SUS, abertos e comunitários, tornando-se referência no tratamento de pessoas que sofrem com transtornos mentais, psicoses, neuroses graves e outros quadros que justifiquem seu atendimento nesse local de cuidado. Eles têm como objetivo ofertar atendimento à população de sua área de abrangência, realizar atendimento clínico, acompanhar o usuário no seu percurso terapêutico, trabalhar a reinserção social, seja pelo trabalho, lazer ou cidadania (Ministério da Saúde [MS], 2004). O CAPSi constitui um dispositivo de reordenamento da rede de atenção à saúde mental, organizando-se a partir dos pressupostos da Reforma Psiquiátrica. As políticas de saúde buscam se efetivar através de leis, portarias e normativas, que estabelecem princípios orientadores para as práticas assistenciais, visando a garantia do cuidado e dos direitos dos usuários. Observamos que as práticas não se configuram apenas por leis e por decretos. Os trabalhadores da saúde são constituídos em um processo social no qual também exercem linhas de forças que contribuem para a constituição de uma determinada infância e de uma prática de atenção a ela direcionada. A contradição é que, sendo estas linhas de força perpassadas por valores pessoais e saberes instituídos, a prática de cuidado pode tanto produzir algo novo e instituinte, segundo os objetivos da política de saúde, como também pode reproduzir aspectos que a própria política visava combater - como os processos de exclusão. Trata-se do paradoxo apontado por Barros (2003) ao afirmar que os CAPS necessitam de institucionalidade enquanto uma possibilidade de cuidado territorializada. Mas que não devem institucionalizar-se no sentido de cronificarse, de deixar de rever suas práticas e a que se destinam: à autonomia ou à exclusão. Nesse sentido, torna-se pertinente retomarmos alguns autores que nos auxiliam a pensar a infância enquanto produção social e histórica, assim como seus processos de patologização e institucionalização ao longo da história.

\section{A Infância como Produção Social e Histórica}

Partimos da concepção de que a infância é uma produção histórica e social, conforme contribuições de Ariès (1978) e De Mause (1991). Alguns autores têm criticado as abordagens a-históricas e descontextualizadas que configuram a infância como um fato natural, universal e homogêneo. Narodowski (1993) considera a infância como um fenômeno histórico e não natural, sendo características: a sujeição da criança a um outro, a dependência e obediência ao adulto em troca de proteção. Segundo Boarini e Borges (1998), estender o sentimento de infância "burguês" a todas as crianças é tratar a infância como a-histórica e, portanto, idealizada.

Observamos variações nas concepções de infância ao longo da história, assim como variações entre diferentes sociedades e dentro de uma mesma sociedade. São infâncias diferentes em estratos diferentes da população de crianças. A história da infância é fortemente marcada pelos discursos médicos e juristas. Bulcão (2002) apresenta a construção de duas infâncias diferentes, uma associada ao conceito de menor, constituída por crianças pobres, abandonadas que perambulavam pelas cidades, às vezes deslizando para a delinquência. Para elas, os estabelecimentos destinados eram as cadeias, os orfanatos, os asilos, os manicômios etc. A outra construção toma o conceito de criança conectada a instituições como família, escola, sem a necessidade de atenção "especial", reforçando a produção de infâncias desiguais.

Hillesheim e Guareschi (2007), ao problematizarem os discursos da Psicologia, em especial a noção de infância trabalhada pela psicologia do desenvolvimento, colocam que tais discursos não podem ser analisados sob a perspectiva do verdadeiro/falso. As teorias são invenções que produzem discursos, e estes instituem padrões de normalidade no desenvolvimento que não podem ser naturalizados.

Nesse estudo, tomamos a infância não como uma fase, conforme Kohan (2004), mas como ruptura em um tempo e história, em que não há fixação do que se deve ou pode ser, onde não hávendo espaços para rótulos e estigmas. A infância, aqui, assume a marca de uma intensidade, intensidade de duração, tornando-se muito mais do que uma etapa da vida, uma potência, uma força vital.

Assim, queremos falar de infâncias capturadas, mas também daquelas que habitam outras temporalidades, que irrompem a história como resistência e criação. Vamos nos referir às infâncias que "resistem aos movimentos concêntricos, arborizados, totalizantes e totalitários" (Kohan, 2004, p. 5). Onde há espaços de não fixação do 
que alguém pode ser ou pode vir a ser, em que não haja a antecipação da experiência do outro.

Podemos estender essa análise para pensarmos que o CAPSi não só atende uma infância "dada”, como também participa da produção de um determinado tipo de infância, desde sua organização na acolhida dos novos usuários, nas escolhas de projetos terapêuticos, como no critério de "patologia" para esse ingresso, bem como os critérios para a alta do serviço.

\section{Patologização e Institucionalização da Infância: Alguns Apontamentos}

A patologização e institucionalização constituem importantes marcadores na constituição de infâncias. O movimento de expansão do número de categorias diagnósticas incluídas nos principais sistemas classificatórios (DSM e CID-10) tem trazido problematizações sobre as fronteiras do normal e do patológico, tema já abordado por Serpa Jr (2003). A esse movimento de aumento do número de diagnósticos e/ou classificações, englobando cada vez mais comportamentos antes considerados "normais", dá-se o nome de patologização.

A psiquiatria infantil emerge de um processo de tutela do social, para o qual convergiram os interesses profiláticos dos psiquiatras e as exigências disciplinares dos aparelhos sociais, e não da descoberta de uma patologia especificamente infantil (Vorcaro, 2011). A autora enfatiza o movimento pelo qual a psiquiatria se utilizou, recorrendo ao recurso diagnóstico como definição da condição da criança diante de uma infância que produz um mal-estar na sociedade. Esse procedimento funciona como um instrumento de controle: ao mesmo tempo em que responde as demandas de familiares, educadores, profissionais de saúde, utiliza-se de classificações etiológicas e nosográficas para direcionar ações terapêuticas que recolocam o projeto da normalidade e adaptação, cessando com isso o mal-estar produzido pela infância enquanto um risco ao ideal social que ela representa.

Dessa forma, entendemos que a produção da infância é atravessada por diferentes instituições, que vão configurando um movimento de patologização e psiquiatrização. Foucault (2006), ao analisar a questão da infância e sua anormalidade no contexto europeu dos séculos XVIII e XIX, coloca que a infância foi um dos alvos de difusão do poder psiquiátrico, uma espécie de "suporte" do processo de psiquiatrização. Para o autor, a psiquiatrização da criança não passou pela criança louca ou pela loucura da infância, mas antes pela criança imbecil, a criança idiota, que será chamada em seguida de criança retardada. É através da criança não-louca que a psiquiatrização da criança se produziu, e logo, essa generalização do poder psiquiátrico.
A partir da segunda metade do século XIX, de acordo com Ribeiro (2006), criam-se abrigos, colégios, jardins de infância e creches para a orientação pedagógica e o cuidado dessa população. As crianças "anormais" dividiam o espaço do manicômio com os adultos, e o Estado não era o responsável pelo cuidado infantil. Como a imbecilidade e a idiotice não eram consideradas doenças, aparecem na infância certos estados que são considerados desvios em relação a uma norma, a categoria da anomalia. Fonseca (2002) refere ainda que a captura dessa categoria pela medicina e sua psiquiatrização possibilitaram a disseminação do poder psiquiátrico.

Pensar o cuidado para as crianças e adolescentes no Brasil implica em analisar os diversos processos que atravessam a sociedade e de que maneira afetam a população. Ao analisarmos as transformações no campo do cuidado em saúde mental, somos levados a refletir sobre a produção histórica, apontando os saberes, discursos e práticas instituídas em determinados períodos e produzindo verdades sobre o sofrimento infanto-juvenil. A história se constitui em um campo de forças no qual determinadas práticas são hegemônicas, assumindo o estatuto de verdades incontestáveis.

No contexto atual, vemos crianças e adolescentes com trajetórias de exclusão, em que a escola lhes atribui rótulos, as famílias são tidas como desestruturadas, fugindo do modelo de família normatizada, possuindo péssimas condições de moradia, caracterizando um problema social que solicita e justifica algumas intervenções. "Dessa forma se instala uma lógica onde a exclusão produz equipamentos de assistência e proteção. Algumas políticas de prevenção se propõem a intervir nessas situações emergindo como um mecanismo de normatização da vida" (Gomes \& Nascimento, 2003, p. 322).

Podemos dizer que a Medicina Higienista não teve interesse na infância com seus desvios, e não dirigiu a elas práticas especializadas. Nos textos médicos, as crianças defeituosas eram citadas como fruto do desregramento moral e casamentos consanguíneos. Dentre os defeitos estavam a surdez, mudez, idiotia, epilepsia. O higienismo começa a se aproximar da infância e das famílias pobres com o intuito de prevenir futuros fardos para a sociedade, em que a relação pobreza-periculosidade começava a se constituir (Foucault, 2001).

Com a mudança na ordem econômica e social, e o estabelecimento do capitalismo liberal-burguês, ocorre um reordenamento das cidades e dos serviços públicos. Essa europeização produziu mudanças no modo de ser das populações: o que antes era coletivo começa a ser individualizado, ocorre uma privatização das condutas, e os médicos se engajam nessa reestruturação recomendando comportamentos e ações. Observa-se, com isso, uma 
mudança nos sentimentos relacionados à infância, construída no decorrer da história. O olhar estrangeiro produziu um movimento de patologização dos comportamentos inerentes a uma cultura (Foucault, 2001; Rizzini, 2004).

Para Lobo (2003), nesse período, a infância era vista como uma fase da vida a qual deveriam ser atribuídas particularidades diferentes dos adultos, práticas especiais de conservação e educação, e de discursos médico-pedagógicos preventivos e normalizadores. "Essa criança como objeto ao mesmo tempo de cuidados e saberes especializados, produzida no recesso de uma família intimizada por valores burgueses e culpabilizada de antemão pelos possíveis desvios de sua criação" (Lobo, 2003, p. 296).

Com isso, um conjunto de medidas asseguradas pela lógica higienista com inspiração normativo jurídica é engendrado nesse discurso hegemônico da criança como o futuro cidadão da sociedade, ficando o cuidado dessas crianças e adolescentes atrelados à tutela, na sua grande maioria, das instituições filantrópicas e caracterizando-se pela permanência em instituições fechadas, como orfanatos, asilos e abrigos (MS, 2005; Pereira, 2003; Rizzini, 1995).

A história mostra que a assistência infantojuvenil se caracterizou pelo predomínio do confinamento em espaços fechados (orfanatos, internatos etc.), como medida de proteção. Essa necessidade de controlar o social está relacionada ao modo de produção capitalista, no qual a vigilância institucionalizada da infância estabelece uma disciplinarização em que a tutela e a coerção são tomadas como medidas de proteção. Também as crianças são objeto de um controle sobre o tempo, sobre o corpo, sobre a vida.

A atenção em saúde mental para crianças e adolescentes no SUS tem em seu histórico a crítica ao ideário protecionista circunscrito num modelo de institucionalização, que contribuía para a segmentação e não integração dessa população. Os avanços políticos e econômicos contribuem ao longo da história da assistência a essa população para a construção de concepções acerca da representatividade desse público para o desenvolvimento do país. Através das novas portarias e leis, o que se pretende é a tentativa de estabelecer outras formas de cuidado rompendo com essa lógica de exclusão e normatização da vida. Mas o que se estabelece como regra não dá garantias quanto à mudança na práxis, pois o passado se atualiza no presente.

\section{Método}

Nessa pesquisa, utilizamos como ferramenta metodológica a abordagem cartográfica. Ao entender a cartografia como um movimento de percorrer paisagens subjetivas, vamos escolhendo determinados instrumentos, lugares, momentos que configuram a pesquisa. A cartografia coloca-se como uma possibilidade de orientação na trajetória de pesquisa, pois se propõe a estudar a dimensão processual da subjetividade. Ao tomá-la enquanto proposta metodológica, precisa-se ter claro que subjetividade e produção são indissociáveis, engendradas numa rede processual. Portanto, cartografar é acompanhar um processo, e não representar um objeto. As configurações subjetivas, segundo Kastrup (2007), não apenas resultam de um processo histórico, mas portam em si mesmas o princípio da processualidade e guardam a potência do movimento. A produção de subjetividade vai se dando num campo de forças, um rizoma, constituído de vetores heterogêneos (econômicos, sociais, políticos, tecnológicos etc.). Kastrup (2008) diz que a cartografia é um método que distingue, mas não separa pesquisa e intervenção. Segundo a autora

No caso da cartografia, a atividade de fazer o mapa de um campo de forças pode ser suscitada pelo desejo de modificar um estado de coisas e mesmo de interferir no processo em questão, o que pode acabar por alterar os contornos do mapa. Tudo isso revela uma ligação entre a cartografia e o movimento do território cartografado. A intervenção pode se fazer junto com a pesquisa e a pesquisa não se limita ao campo do saber. (Kastrup, 2008, p. 465)

Ao tomarmos a cartografia como intervenção, consideramos o plano da experiência no qual, segundo Barros e Passos (2009), o conhecer e o fazer não se encontram separados e operam na transformação da realidade. $\mathrm{O}$ pesquisar nos coloca em contato com um universo complexo, tensionando o uso de metodologias que permitam a mudança de direção nos processos de criação.

O campo escolhido para essa pesquisa foi um Centro de Atenção Psicossocial para crianças e adolescentes (CAPSi) localizado no Rio Grande do Sul. O nome do CAPS e o município onde se localiza serão mantidos em sigilo, seguindo os preceitos éticos acordados com a equipe. Esta pesquisa seguiu as regulamentações da resolução 196/1996', do Conselho Nacional de Saúde (CNS), tendo sido aprovada pelo Comitê de Ética em Pesquisa do Instituto de Psicologia da UFRGS.

Barros e Kastrup (2009) consideram necessária a criação de dispositivos através dos quais a cartografia possa operar. O dispositivo desloca o que se encontra enrijecido para a invenção, produzindo outros efeitos de produção e transformação. Em nossa pesquisa, utilizamos como dispositivos de produção dos dados: grupos focais, observação participante e o diário de campo.

1 A pesquisa foi realizada no ano de 2009, antes da mudança da Resolução 196/1996 para Resolução 466/2012, Conselho Nacional de Saúde (CNS) 
Foram realizados cinco grupos focais, respectivamente: com residentes multiprofissionais, com os técnicos de nível superior, com os técnicos de ensino médio (oficineiros), com grupo de apoio (serviços gerais, auxiliar de cozinha) e um último grupo com a participação de todos, com caráter de integração dos dados e devolução ao grande grupo das produções de cada grupo.

Assim, realizamos cinco grupos, grupos dispositivos (Barros, 2007), que enunciaram práticas e funcionamentos, permitindo percorrer os discursos sobre a infância. Os grupos foram realizados com os profissionais, divididos conforme sua função no organograma do serviço, e tiveram, cada um, duração de uma hora e meia. Utilizamos questões disparadoras que aqui chamaremos de interrogantes. Os grupos possibilitaram acompanhar as linhas de enunciação, de visibilidade, de força, de subjetividade e as de resistência e fuga ${ }^{2}$, compondo, assim, a cartografia. Ao final de cada grupo, foi construída uma síntese que seria compartilhada com todos em um quinto encontro. As sínteses assumiram diferentes formas, e foi mantido o sigilo de quem as produziu.

No quinto grupo, utilizamos essas formas como analisadores da produção de infância no CAPSi, e de como os profissionais significavam aquele espaço. Podese questionar também a divisão dos grupos como um nó ainda presente no processo de trabalho de equipes em saúde, no qual se mantém a hierarquia de saberes a partir dos "especialismos". Percebemos todos esses movimentos e os atravessamentos presentes no modo de trabalho dessa equipe, mas nossa finalidade e inserção nesse CAPSi foi através da pesquisa, com um determinado recorte de tempo e objetivos.

As observações participantes foram caracterizadas pelo acompanhamento das atividades realizadas pelos profissionais que trabalhavam no serviço, durante quatro meses, três turnos por semana, com uma média de doze horas semanais. Entre as atividades acompanhadas, destacamos: as oficinas, o centro de atenção diária (CAD), o acolhimento e as reuniões de equipe. O CAD é um espaço destinado para as crianças que estão em sofrimento mais intenso e onde os profissionais são convocados a interagir com a diversidade. Nas reuniões de equipe, há um espaço para a discussão dos casos atendidos. Entendemos que a escolha de um caso para a discussão pode constituir-se em analisador do modo como a infância está sendo compreendida e produzida. Tomamos o conceito de analisador da perspectiva institucionalista, sendo entendidos como dispositivos que permitem a explicitação de conflitos e sua resolução. Podem ser analisadores artificiais ou construídos, em que algum recurso externo manifesta o jogo de forças existente. Ou,

2 Essas linhas foram trabalhadas por Deleuze no texto O que é um dispositivo, de 1990. ainda, podem ser analisadores espontâneos ou naturais, produzidos pela própria vida histórica, social, libidinal e natural (Baremblitt, 1996).

No período em que essa pesquisa acontecia, existiam quinze espaços destinados a atividades coletivas, distribuídos entre grupos e oficinas. Entre eles encontramos: grupo de cuidadores, grupo de caminhada, grupo de adolescentes, oficina de teatro, oficina de brinquedos, oficina de leitura, oficina de culinária, jogos cooperativos, oficina de bijuteria, oficina de beleza, oficina de pintura, oficina de fuxico, grupo de dança, espaço de vídeo e oficina de música, distribuídos nos turnos de atendimento durante a semana.

Os grupos focais foram gravados e transcritos, produzindo cenas para o processo de análise. As observações foram registradas em diário de campo. O diário de campo constituiu-se como ferramenta importante para o registro das observações. Nele são mantidos os registros da experiência no campo, o que se passa nos encontros entre o pesquisador e o campo, entre o pesquisador e as pessoas que habitam esse lugar, além de problematizações e reflexões realizadas a partir das atividades acompanhadas (Barros e Kastrup, 2009). A pesquisa gerou três linhas de análise, que expressam a infância em três movimentos: patologização, institucionalização e invenção. Neste artigo, desenvolvemos a primeira linha de análise, que remete aos processos de psiquiatrização e patologização da infância, analisando as práticas que os expressam e alguns de seus efeitos.

\section{Movimentos de Psiquiatrização e Patologização da Infância}

No percurso das crianças pelo CAPSi, percebemos que várias marcas vão sendo impressas em seus processos de subjetivação. Uma dessas marcas ocorre pelo processo de atribuição de um diagnóstico às crianças. Os efeitos dessas práticas são sentidos desde o momento em que as crianças chegam pela primeira vez ao serviço. Em um dos acolhimentos em grupo com crianças, chamou-nos atenção o que essas práticas representavam na vida de cada um, e como eram sentidas de maneiras diferentes. Ao serem questionados se sabiam o motivo do encaminhamento para o CAPSi, emergem as falas:

- Minha mãe acha que eu sou louquinho, me trata feito um. Só de estar aqui é a confissão assinada de que sou um "mentais severos e persistentes". Não tenho nem severo nem não severo, não tenho problema nenhum. $-\mathrm{M}, 14$ anos.

- Para ajudar as pessoas para ficar bem, acho que não é para louquinho, porque louco é no hospício. B, 12 anos.

- Não precisa ser imbecil para estar aqui. Mi, 10 anos. (Acolhimento em grupo com crianças, fragmentos do 


\section{Diário de Campo).}

O diagnóstico enquanto reconhecimento da patologia da criança é construído a partir da observação. A observação da criança pressupõe a comparação de suas manifestações com aquelas catalogadas, reencontrando a classe do transtorno que ela representa, explicando-a como uma categoria (Vorcaro, 2011, p. 222). Esse ideal classificatório na busca pela garantia da objetividade afasta as manifestações subjetivas.

Segundo Vorcaro (2011), a nomeação diagnóstica pode adquirir tamanha valência que destitui o nome próprio da criança, substituído pela identidade social conferida pelo nome da síndrome em que a medicina localiza. Estabelece assim sua nova filiação, dada pelo nome da síndrome, que baliza, referencia e justifica os atos, as falas e condutas da criança. Dessa forma, inserir a criança no laço social a partir dessa determinação, por exemplo, mentais severos e persistentes, é reduzi-la ao registro médico, amputando sua singularidade subjetiva (Vorcaro, 2011, p. 228).

A legislação que regulamenta os CAPS preconiza o atendimento de pessoas com transtornos mentais graves, severos e persistentes. Opera como agenciador de entradas, mas chama a atenção que ao mesmo tempo em que orienta a construção de um modelo pautado no modo psicossocial, produz outros acoplamentos, pois o discurso da psiquiatrização atravessa as novas práticas. A nomenclatura utilizada é outra, toma emprestado outra roupagem, a de "transtornos mentais severos e persistentes", mas continua sendo vivenciada por alguns sujeitos como sinônimo de loucura e estigmatização.

O modo psicossocial, segundo Costa-Rosa (2000) contrapõe o modelo psicossocial ao modelo asilar. Este é caracterizado pelo modo de relação sujeito-objeto, biomédico e positivista, buscando a adequação do indivíduo ao meio, afirmando práticas segregadoras e assujeitadas. Já o modelo psicossocial é caracterizado pela superação da ética da adaptação pela ética da implicação subjetiva e sociocultural dos usuários e instituições de saúde, fortalecendo a integralidade das ações no território.

Eis um grande paradoxo desses estabelecimentos, pois nascem dentro de uma nova configuração política e social, imersos em normatizações que tentam assegurar um modo de cuidado pautado na singularidade, mas correm o risco, desde sua inauguração, de reproduzir justamente aquilo que buscam combater. A existência desses equipamentos é fundamental para a garantia de um modo de cuidar, mas não exclui a atenção e análises constantes sobre seu funcionamento.

A partir da análise dos relatos das crianças e adolescentes, percebemos que o significado de "transtornos mentais, severos e persistentes" é vivido por alguns com o mesmo peso da loucura, pois para essa criança a experiência de sofrimento psíquico o faz ter a história marcada por internações. Reconhece as características necessárias para ter acesso ao serviço, bem como aquelas que costumavam vir associadas aos ditos loucos. Para outras crianças/ adolescentes, o CAPSi tem como finalidade ajudar aqueles que precisam. O discurso da patologização ainda não se dobrou sobre eles. Para eles, o lugar do louco continua sendo no hospício, explicitando que a necessidade da existência de espaços para loucos ainda é presente em nossa sociedade. São crianças que foram subjetivadas em outro contexto sócio-político, mas os efeitos do desejo de manicômio ainda se fazem presentes entre todos. O desejo de manicômio, segundo Lavrador e Machado (2001), consiste em um desejo de enclausurar, esquadrinhar e controlar o outro. Trata-se de um movimento que busca localizar e segregar a diferença, seja através de dispositivos fechados (como os manicômios) ou de modos de controle a céu aberto.

Outro analisador importante relaciona-se ao modo como os "casos" são discutidos nas reuniões de equipe. Durante as reuniões são discutidos, em média, vinte "casos". Em uma das reuniões, trinta e dois "casos" foram discutidos. Os relatos eram centrados nas evoluções diagnósticas, mudanças de medicação, alterações nos projetos terapêuticos, comunicação de altas, envolvimento com a justiça ou outros órgãos externos à saúde, elaboração de laudos. Mas pouco ou quase nunca vi crianças presentes naqueles relatos. Ou seja, não estava presente nos relatos aquilo que é um movimento da infância, como apontado por Kohan (2004): a singularidade, a criatividade, a capacidade de reinvenção.

Chama atenção a presença das classificações diagnósticas como centralidade na história dessas crianças. A avaliação tem priorizado o fechamento de um diagnóstico, e todo o seu percurso pelo CAPSi está marcado pela manutenção da doença, através da afirmação de um conjunto de sintomas.

Primeiro diagnóstico TDAH (Transtorno do Déficit de Atenção com Hiperatividade), oposição e desafio - risco para desenvolver transtorno de conduta. Pensam em alguma coisa mais direcionada a transtorno de conduta oficinas e tal. Pertence ao bonde. Esse vai pra a FASE daqui a pouco. (Reunião de Equipe, fragmentos do diário de Campo)

Uma estrutura que privilegia a produção da doença acaba utilizando estratégias pautadas nessas concepções, sendo a cura o objetivo final. Alguns fragmentos do diário de campo denotam enunciados presentes nas práticas, entre eles o de salvação da alma das crianças, presentes desde 
o século XVIII. Além disso, a ideia da criança como um futuro cidadão.

Portador da loucura da família; que exige muito dele; caso que escapa da mão; caso que não temos em nossas mãos. Mau prognóstico. (Reunião de Equipe, fragmentos do diário de Campo)

Não vi nenhum transtorno muito claro, só alguns impulsos, avaliar nos espaços do CAPS. (Reunião de Equipe, fragmentos do diário de Campo)

A partir disso nos perguntamos: quando o caso é uma criança ou quando a criança não é um caso? O caso é uma forma assumida em um momento da vida, assumindo determinada configuração para auxiliar quem cuida da criança a compreendê-la melhor, uma vez que reúne alguns elementos e informações que fazem parte da singularidade da criança. No entanto, reduzir o caso ao diagnóstico pode significar o aprisionamento da criança em uma única direção dos processos de subjetivação. Nesse processo, as práticas de cuidado decorrentes irão restringir a criança à exploração do mundo por tomar como verdade que doentes têm limitações. Assim, qualquer ação da criança será tomada como sintoma, e, a partir disso, nada escapará aos olhos atentos e vigilantes dos profissionais da saúde e da família. Segundo orientações da Coordenação Nacional de Saúde Mental (CNSM, 2009), o diagnóstico possui um caráter universalizante e homogeneizador. Ele pode fazer parte da clínica em alguns momentos. Porém, a clínica não pode assentar-se somente nele, devendo principalmente abordar o que há de singular, de diferente, único. Ao propor a noção de clínica ampliada, busca-se justamente romper com o modelo que se institucionalizou na saúde, focando somente os aspectos que universalizam e homogeneízam o sujeito.

Passa uma coisa muito ruim, pequeno horrorosinho; Mau prognóstico. (Reunião de Equipe, fragmentos do diário de Campo)

O fragmento acima traz outra questão importante no movimento de patologização da infância. Quais são os efeitos de enunciados como: a criança tem um bom ou mau prognóstico? Como podemos afirmar que uma criança não encontrará outras formas de viver seu sofrimento? Ao entender a criança como um mau prognóstico, encerra-se nela todas as possibilidades de inventar outras estratégias de experimentar seu sofrimento, além de excluir outros elementos importantes na sua constituição. A família passa a ser algo periférico, assim como o modo como a criança vive, se alimenta, o local onde estuda, a relação com os grupos sociais, entre outros, desconsiderados como coprodutores de adoecimento. Esta perspectiva fortalece o processo de subjetivação individualizante, característico da contemporaneidade (Nardi \& Silva, 2004).

A busca pela remissão dos sintomas presentes nas crianças e o retorno à norma acabam gerando frustração nos profissionais, pois estes possuem expectativas de alcançar uma infância sem problemas, colocando as crianças como "futuros cidadãos". Através dos grupos, percebemos que os trabalhadores sofrem quando as crianças não respondem aos planos pensados por eles. Esse sofrimento acaba limitando a abertura para qualquer movimento diferente que a criança realize, pois se espera um determinado modo de agir. $\mathrm{O}$ que foge do esperado acaba não sendo reconhecido. A não resposta da criança gera no profissional certa desistência, pois o investimento direcionado a elas é tomado como fracasso e perda de tempo, uma vez que as respostas esperadas não virão.

Tem casos que a gente não tem o que fazer. (Grupos, fragmento do diário de campo)

Mas, afinal, o que se espera fazer? Talvez o que a criança esteja demandando não esteja sendo escutado pelas equipes, seja pelos atravessamentos de uma concepção de universalização da infância ou da concepção do que é função desse serviço. Torna-se relevante, neste contexto, a discussão sobre a diferença entre cura e cuidado. A cura baseia-se na ideia de recuperação de um estado anterior, perdido, na qual supostamente haveria uma "normalidade". A noção de cuidado, no entanto, pauta-se em uma nova ética da relação e da atenção, reconstruindo o percurso de cada sujeito no seu sofrimento e deslocando a solução do problema para a afirmação da ação terapêutica como ação de transformação institucional (Rotelli, Leonardis, \& Mauri, 1990).

As classificações diagnósticas também influenciam a distribuição e organização dos grupos e oficinas terapêuticas nos CAPS. Os tipos de oficinas e grupos criados nos serviços buscam contemplar e desenvolver com as crianças e adolescentes a sua reinserção social, trabalhar as suas dificuldades e potencialidades, configurar-se como espaço de ludicidade. Porém, observamos que muitas vezes as crianças desconhecem o motivo de estar participando de determinadas atividades, mas o encontro com outras crianças no espaço organizado e com determinadas tarefas faz com que se produzam deslocamentos. Ao mesmo tempo em que a escolha por determinados espaços coletivos se dá através da discussão e decisão dos profissionais, considerando a classificação diagnóstica; para as crianças, essa determinação nem sempre se faz presente, permitindo a ela outra circulação pelos espaços. 
Essa definição quanto às atividades que cada criança poderá participar pode ser compreendida a partir da utilização e incorporação do projeto terapêutico singular (PTS) no cotidiano das práticas no CAPS. O PTS proporciona a atuação integrada de todos os profissionais da equipe, valorizando outros aspectos além do diagnóstico psiquiátrico e da medicação no tratamento dos usuários. A equipe elabora o projeto a partir da escuta do usuário, incluindo-o nessa elaboração, pois será corresponsável pelo seu tratamento (Ministério da Saúde [MS], 2009). Ao incorporar essa lógica no trabalho, a equipe pode discutir ou negociar com o usuário-criança os espaços que serão incluídos no seu plano de cuidado, buscando o olhar e a significação que a criança atribui ao local. Desconsiderar esse olhar e contribuição pode distanciar a criança da sua escolha e significações do espaço, produzindo experiências mais massificadas.

Na distribuição das atividades deste CAPSi, há espaços destinados para os usuários considerados "mais graves" e outros para aqueles considerados "não graves", imprimindo uma hierarquia nas patologias. Quando considerada grave, é indicada a participação no Centro de Atenção Diária (CAD). Esse espaço era configurado como o lugar para quem estava em tratamento intensivo. As crianças podiam ser inseridas no CAPS de diferentes maneiras, conforme a frequência na participação das atividades, relacionada ao momento e sofrimento de cada criança. O que se preconiza para a oferta de cuidados nos CAPS é o atendimento para pessoas em crise. Para atender a essa demanda os serviços se organizam de diferentes maneiras: através de grupos, oficinas, acompanhamento terapêutico, atendimentos individuais (MS, 2004). O risco é transformar esses espaços em máquinas de produção patológicas, cujo critério para a participação é o diagnóstico e não o que aqueles espaços podem contribuir para a diminuição e ressignificação do lugar do sofrimento.

A lógica da divisão entre graves e não graves nos remete àquelas divisões realizadas nos manicômios, entre os pavilhões-asilo e pavilhões-escola, sendo o critério de entrada ser recuperável ou irrecuperável (Zuquim, 2002). Com isso, observamos como vamos produzindo os anormais e como o poder psiquiátrico atravessa as práticas atuais.

Essa guria é aquela psicótica? Podre de psicótica! Essa paciente é crônica, regressão, com ela o movimento é ao contrário, sai da Oficina e vai para o CAD. (Reunião de Equipe, fragmentos do diário de Campo)

Ela está estagnada, é uma menina retardada, na oficina de brinquedo as coisas vêm se repetindo. Ir para o CAD? Trabalhar com a mãe? Em time que se tá ganhando não se mexe. Ela permanece nessa oficina. Essa menina vai fazer 18 anos na oficina de brinquedo. (Reunião de Equipe, fragmentos do diário de Campo)

A mudança no plano terapêutico e a circulação das crianças pelos espaços terapêuticos têm sido marcadas pela patologia. Através dos relatos, percebemos que a entrada em uma oficina significa estar fora da crise, enquanto o CAD ocupa o lugar de acolhimento de todos na crise. Entendemos que o CAD possui a função de permitir a livre circulação das crianças, onde possam ser acolhidas em atividades diversificadas. Parece-nos que o CAD vem se engessando, perdendo sua funcionalidade e tornandose um lugar associado à crise. Para que o CAD ocupe a função de livre circulação e expressão, os contratos nos grupos e oficinas precisam ser esclarecidos e revistos a todo momento, incluindo sempre a criança na sua construção. Conforme Rotelli, Leonardis e Mauri (1990), a transformação nos modos como as pessoas são tratadas não busca mais a solução-cura, e sim, a transformação do seu sofrimento, percorrendo a complexidade dos modos de cuidado. Para os autores "a ênfase não é mais colocada no processo de cura, mas no projeto de invenção de saúde e de reprodução social do paciente” (p. 30).

\section{Considerações Finais}

O trabalho dos profissionais e a forma como a sociedade vê a criança estão baseados em alguns paradigmas. Discutimos aqui a patologização e a psiquiatrização. Buscamos compreender os modos como a infância vai sendo produzida nesse encontro com o CAPSi. E, a partir desse encontro, como a criança vai sendo afetada e como afeta outrem. $\mathrm{O}$ encontro resulta na singularidade, na criança como acontecimento. "É quando uma questão de dinâmica (de atividade) entra em jogo que o acontecimento tem lugar, porque ele (o acontecimento) é sempre produzido por corpos que se entrechocam, se cortam ou se penetram, a carne e a espada" (Deleuze \& Parnet, 1998, p. 78). Com o encontro, as forças se manifestam e o acontecimento tem lugar, de modo que aquilo que resulta de um encontro é invariavelmente singular.

$\mathrm{O}$ que surge a partir do encontro com conceitos, formas, equipamentos, quando elementos heterogêneos da criança conjugam-se com outros elementos heterogêneos, faz com que fiquemos cada vez mais distantes de noções de desenvolvimento, de ideias de representação, pois nunca sabemos o que resulta de um encontro, já que este se localiza no imprevisível (Marcello, 2009).

As questões trazidas por Marcello (2009) exprimem algumas inquietações que acompanharam a tessitura dessa pesquisa: como, no decorrer dela, não cair na armadilha disciplinadora dos corpos? Como o CAPS pode produzir desvios e não produzir somente os "mentais severos e 
persistentes"? Como ressignificar com as crianças o lugar de quem tem algum sofrimento? Como deslocar o olhar daquilo que as caracteriza como problema?

Torna-se importante tensionar e fugir da noção de uma identidade infantil, de uma "entidade criança" como um ser único, fixo e universal, em que se apresenta um conjunto de comportamentos e características e deles se espera a mesma resposta. A criança deixa de ser um polo aglutinador e passa a ser "um campo de forças, de intensidades, de relações diferenciais, de elementos indiferenciados" (Marcello, 2009, p. 615).

O CAPSi pode estar no lugar de agenciador de novos encontros para que desvios aconteçam e outras experiências sejam possíveis. O CAPSi como o lugar de encontro, onde diversas instituições se cruzam, permitindo que o encontro das crianças se dê com cada uma dessas instituições que atravessam as práticas e dão um contorno ao serviço.

Dentro desta perspectiva, não se quer dizer que não haja sofrimento na loucura, mas sim que isso não invalida o sujeito. Na verdade, é impossível pensar a sociedade sem sofrimento, principalmente levando-se em conta todos os imperativos de felicidade ditados pelo capitalismo, fazendo com que o sujeito viva num constante estado de angústia.

O lugar da saúde mental neste contexto é sempre equilibrista, daí a necessidade de estarmos sempre colocando nossa prática em análise - o que eu faço; como faço; para que faço? - numa tentativa de resistir à cristalização de práticas adaptativas e assujeitadoras.

Para finalizar, cabe apontar que este estudo assentase sobre a ideia de problematização. Entendemos que o exercício da problematização, longe de fragilizar os serviços, os fortalece, pois recoloca questões para o pensamento.

\section{Referências}

Ariès, P. (1978). História social da criança e da família. Rio de Janeiro: LTC.

Coordenação Nacional de Saúde Mental. (2009). Curso de capacitação para novos gestores de saúde mental. Brasília: Autor.

Ministério da Saúde. Secretaria de Atenção à Saúde. Política Nacional de Humanização da Atenção e Gestão do SUS. (2009). Clínica ampliada e compartilhada. Brasília: Autor.

Ministério da Saúde. Secretaria de Atenção à Saúde. Departamento de Ações Programáticas Estratégicas. (2005). Caminhos para uma política de saúde mental infanto-juvenil. Brasília: Autor.

Ministério da Saúde. Secretaria de Atenção à Saúde. Departamento de Ações Programáticas e Estratégicas. (2004). Saúde Mental no SUS: os centros de atenção psicossocial. Brasília: Autor.

Baremblitt, G. (1996). Compêndio de análise institucional e outras correntes: teoria e prática. Rio de Janeiro: Rosa dos Tempos.

Barros, R. B. (2003). Reforma psiquiátrica brasileira: Resistências e capturas em tempos neoliberais. In Conselho Federal de Psicologia (CFP) (Org.), Loucura, ética e política: escritos militantes (pp. 196-206). São Paulo: Casa do Psicólogo.

Barros, R. B. (2007). Grupo: A afirmação de um simulacro. Porto Alegre: Sulina/Editora da UFRGS.

Barros, R. B., \& Kastrup, V. (2009). Movimentos-funções do dispositivo na prática da cartografia. In E. Passos, V. Kastrup, \& L. D. Escóssia (Orgs.), Pistas do método da cartografia: pesquisa-intervenção e produção de subjetividade (pp. 76-91). Porto Alegre: Sulina.

Barros, R. B., \& Passos, E. (2009). A cartografia como método de pesquisa-intervenção. In E. Passos, V. Kastrup, \& L. D. Escóssia (Orgs.), Pistas do método da cartografia: pesquisa-intervenção e produção de subjetividade (pp.17-31). Porto Alegre: Sulina.

Boarini, M. L., \& Borges, R. F. (1998). Demanda infantil por serviços de saúde mental: Sinal de crise. Estudos de Psicologia, 3(1), 83-108.

Bulcão, I. (2002). A produção de infâncias desiguais: Uma viagem na gênese dos conceitos "criança" e "menor". In M. L. Nascimento (Org.), Pivetes: A produção de infâncias desiguais (pp. 61-73). Niterói, RJ: Intertexto; Rio de Janeiro: Oficina do Autor.

Costa-Rosa, A. (2000). O modo psicossocial: Um paradigma das práticas substitutivas ao modo asilar. In P. D. C. Amarante (Org.), Ensaios de loucura \& civilização (pp. 141-168). Rio de Janeiro: Fiocruz.

De Mause, L. (1991). História de la infância. Madri: Alianza Universid.

Deleuze, G. (1990). ¿Que és un dispositivo? In G. Deleuze, H. L. Dreyfus, M. Frank, A. Glucksmann, J. A. Miller, \& R. Rorty (Eds.), Michel Foucault, filósofo (pp. 155161). Barcelona: Gedisa.

Deleuze, G., \& Parnet, C. (1998). Diálogos. São Paulo: Editora Escuta.

Fonseca, M. (2002). Entre monstros, onanistas e incorrigíveis: As noções de "normal" e "anormal" nos cursos de Michel Foucault no Collège de France. In M. Rago, L. B. Orlandi, \& A. Veiga-Neto (Orgs.), Imagens de Foucault e Deleuze: Ressonâncias nietzschianas (pp. 239-253). Rio de Janeiro: DP\&A.

Foucault, M. (2006). O poder psiquiátrico: curso no Collège de France (1973-1974). São Paulo: Martins Fontes. 
Foucault, M. (2001). Os anormais: curso no Collège de France (1974-1975). São Paulo: Martins Fontes.

Gomes, A., \& Nascimento, M. L. (2003). Infância, adolescência e proteção: Produção histórica e crítica do presente. In A. M. Jacó-Vilela, A. C. Cerezzo, \& H. B. Rodrigues (Orgs.), Clio-Psyché paradigmas: historiografia, psicologia, subjetividades (pp. 321326). Rio de Janeiro: Relume Dumará, FAPERJ.

Hillesheim, B., \& Guareschi, N. (2007). De que infância nos fala a psicologia do desenvolvimento. In $\mathrm{N}$. Guareschi, \& S. Hüning (Orgs.), Implicações da psicologia no contemporâneo (pp. 83-102). Porto Alegre: EDIPUCRS.

Kantorski, L. P., Jardim, V. M. R., Wetzel, C., Olschowsky, A., Schneider, J. F., Resmini, F., ... \& Sousa, A. S. (2009). Contribuições do estudo de avaliação dos Centros de Atenção Psicossocial da região sul do Brasil. Cadernos Brasileiros de Saúde Mental, 1(1), 1-9.

Kastrup, V. (2008) O método da cartografia e os quatro níveis da pesquisa-intervenção. In L. R. Castro, \& V. L. Besset (Orgs.), Pesquisa-intervenção na infância e juventude (pp. 465-489). Rio de Janeiro: Trarepa/ FAPERJ.

Kohan,W. (2004). Apontamentos filosóficos para uma (nova) política e uma (também nova) educação da infância. [Palestra] Gt de "Educação Infantil - 0 a 6 anos", 27 Reunião ANPED. Recuperado de http:// www.anped.org.br/reunioes/27/diversos/te_walter kohan.pdf

Lobo, L. (2003). Higienismo e normalização da infância no Brasil. In A. M. Jacó-Vilela, A. C. Cerezzo, \& H. B. C. Rodrigues (Orgs.), Clio-Psyché Paradigmas: Historiografia, Psicologia, Subjetividades (pp. 291230). Rio de Janeiro: Relume Dumará/FAPERJ.

Lavrador, M. C. C., \& Machado, L. D. (2001). Loucura e subjetividade. In L. D. Machado, M. C. C. Lavrador, \& M. E. B. Barros (Eds.), Texturas da Psicologia; subjetividade e política no contemporâneo (pp. 45-58). São Paulo: Casa do Psicólogo.

Marcello, F. (2009). Sobre crianças e encontros: Singularidades em jogo na estética cinematográfica. Educação \& Sociedade, Campinas, 30(107), 611-630.

Nardi, H., \& Silva, R. N. (2004). A emergência de um saber psicológico e as políticas de individualização. Revista Educação e Realidade, 29(1), 187-198.

Narodowski, M. (1993). Infância e poder: A confrontação da pedagogia moderna. Tese de Doutorado em Educação, Universidade Estadual de Campinas, Campinas, SP.

Onocko-Campos, R., \& Furtado, J. (2006). Entre a saúde coletiva e a saúde mental: Um instrumental metodológico para avaliação da rede de Centros de Atenção Psicossocial (CAPS) do Sistema Único de
Saúde. Cadernos de Saúde Pública, 22(5), 1053-1062.

Pereira, N. N (2003). Novas políticas na área de saúde mental da infância e adolescência: Práticas e concepções teóricas na reinserção psicossocial. Dissertação [Mestrado em Saúde Pública], Escola Nacional de Saúde Pública da Fundação Oswaldo Cruz, Rio de Janeiro.

Ribeiro, P. R. M. (2006). História da saúde mental infantil: A criança brasileira da Colônia à República Velha. Psicologia em Estudo, Maringá, 11(1), 29-38.

Rizzini, I. (2004). A institucionalização de crianças no Brasil: Percurso histórico e desafios do presente. Rio de Janeiro: Ed. PUC-Rio; São Paulo: Loyola.

Rizzini, I. (1995). A arte de governar crianças: A história das políticas sociais, da legislação e da assistência à infância no Brasil. Rio de Janeiro: Instituto Interamericano Del Niño, Editora Universitária Santa Úrsula, Amais Livraria e Editora.

Rotelli, F., Leonardis, O., \& Mauri, D. (1990). Desinstitucionalização, uma outra via. In F. Rotelli, O. Leonardis, D. Mauri, \& F. Nicácio (Orgs.), Desinstitucionalização (pp. 17-59). São Paulo: Hucitec.

Serpa Jr, O. D. (2003). Indivíduo, organismo e doença: A atualidade de o Normal e o Patológico de Georges Canguilhem. Psicologia Clínica, Rio de Janeiro, 15(1), 121-135.

Vorcaro, A. M. R. (2011). O efeito bumerangue da classificação psicopatológica na infância. In A. Jerusalinsky, \& S. Fendrik (Orgs.), O livro negro da psicopatologia contemporânea (pp. 219-229, $2^{\mathrm{a}}$ ed.). São Paulo: Via Lettera.

Zuquim, J. (2002). Pequenos psicopatas: Infância, criminalidade e loucura na primeira república. In E. H. Antunes, \& L. H. S. Barbosa (Orgs.), Psiquiatria, loucura e arte: fragmentos da Historia Brasileira (pp. 123-146). São Paulo: EDUSP.

\section{Endereço para correspondência:}

Michele da Rocha Cervo

Endereço: Br 153, km 7, Departamento de Psicologia,

Riozinho. Irati/PR. - CEP: 84500-000.

E-mail: michelecervo@gmail.com 